\title{
COVID-19 and children
}

\author{
Senka Mesihović-Dinarević* \\ Department of Medical Sciences, Academy of Sciences and Arts of Bosnia and Herzegovina, Sarajevo, Bosnia and Herzegovina
}

Dear editor,

I am writing this letter in two parts:

\section{PART ONE/MAY 20, 2020/}

Most children with a proven coronavirus disease (COVID-19) infection are asymptomatic or have mild symptoms (1).

However, a small number of children have been identified in the past 2 months with developed significant multisystem inflammatory response. All children were treated according to standard protocols. Children with this disease may require hospitalization in pediatric intensive care unit with a multisystem team approach to the disease, which includes pediatricians, infectologists, cardiologists, rheumatologists, immunologists, and epidemiologists (2). This extremely rare disease is curable if diagnosed in time.

This rare syndrome has features in common with other pediatric inflammatory diseases including Kawasaki syndrome, staphylococcal and streptococcal toxic shock syndrome, bacterial sepsis, macrophage activation syndrome, and may present with unusual abdominal pain including elevated inflammation markers. Early recognition of this disease by a pediatrician or family doctor specialist is crucial for the timely treatment and outcome of the disease (3-5).

The new multisystem inflammatory syndrome is a reminder that children have an unusual and rare response to etiological factors.

Kawasaki disease/mucocutaneous lymph node syndrome, that is, generalized febrile illness that carries significant heart pathology, and whose cause is unknown, is vasculitis, which is usually triggered by viruses. In the fight against the virus, the body begins to attack its own blood vessels, it often affects children under 5 years of age, is associated with fever, skin rash, swelling of the glands, conjunctivitis, and, in severe cases, inflammation of the coronary arteries, which is clearly visible by color Doppler ultrasound. The coronary artery dilates, causing a coronary artery aneurysm with the possibility of myocardial infarction in the child. The

Corresponding author: Senka Mesihović-Dinarević, Department of Medical Sciences, Academy of Sciences and Arts of Bosnia and Herzegovina,

Sarajevo, Bosnia and Herzegovina. E-mail: dsenka@bih.net.ba

Submitted: 30 December 2020/Accepted: 04 January 2021

DOI: https://doi.org/10.17532/jhsci.2021.1194 reason for the appearance of this syndrome is not weakened immunity, but an immune reaction that is individual, it can occur in healthy children, when, after overcoming an infection, this phenomenon occurs. If not timely treated, the outcome can be lethal, and if recognized late, permanent consequences can remain on the coronary arteries with a lifetime risk of myocardial infarction. Kawasaki syndrome is treated with immunoglobulin and corticosteroid therapy, along with aspirin, the disease is not infectious but reactive. If parents notice any of these symptoms, fever, and do not know why it occurred, rash and other changes characteristic of Kawasaki, they should immediately take the child to a doctor, pediatrician, or family doctor!

Two of the 20 hospitalized children, according to doctors from Ireland, required intensive care, fortunately, no lethal outcome has been announced so far. These reports of illness in children are an alarm, a warning, and something that is currently being researched in the world by many researchers and scientists. The professor states that she is in contact with pediatricians in our country, as well as England, Italy, and Austria, they exchange opinions and experiences in the treatment of children, monitor epidemiological trends in the world every day, and points out that professionalism, careful, and detailed approach are needed to child and parents, adherence to the instructions of fellow epidemiologists, infectologists, and the Disease Control Board of the respective Ministry of Health, rigorous respect to infection prevention measures, and to follow the pathways of treatment and diagnosis of the disease.

As a member of the Royal College of Paediatricians and Child Health in England, I am weekly informed and up to date with the corona situation in the UK and I am grateful for sharing information such as: Impact, COVID-19 on Child Health - Child Health Services.

On April 28, 2020, the first experiences of doctors from North Italy and Ireland/Our Lady's Children's Hospital from Dublin were published on the inflammatory syndrome in children under 9 years of age associated with COVID-19. Doctors stated that this was a new disease, which can be caused by the coronavirus and the COVID-19 virus, the number of sick children is small; however, as but since they are not $100 \%$ sure due to the lack of a positive test in some patients, they are undertaking a lot of research and state that this situation is worrying. The warning about 
this disease also came from Great Britain, stating that children without diseases of other organ systems died from a rare inflammatory syndrome, which scientists believe is related to the coronavirus. Medical experts from Italy and Great Britain have been researching possible link between the corona pandemic and the focus of severe inflammatory disease among children hospitalized with high fever and dilated coronary arteries.

The disease is similar to Kawasaki syndrome, so I would like to warn pediatricians to be careful in their daily work and consider thoughtfully about this disease.

\section{PART TWO/DECEMBER 16, 2020/}

\section{What is the connection between the infection of children with the coronavirus and the possibility of continuing the child's active participation in sports?}

As time has passed since the beginning of the COVID-19 pandemic/March 2020/, many children who play sports, and have been in contact with corona in the family (father, mother, brother, and sister), or at school or in sports clubs, ask the question of further treatment, or when and with what intensity can they continue to play sports? Also, the same question is asked by children who have overcome the milder form of corona.

Of course, the moderate and severe form of corona with all complications requires hospitalization in the Departments of Paediatric Intensive Care and Therapy or Neonatal Intensive Care and Therapy/in case of a newborn $(6,7)$.

Along with the application of professional world medical literature, evidence-based medicine, as well as the guide of sports medicine published in the British Journal of Sports Medicine in November 2020 (8), the position of fellow pediatric cardiologists in our region is to apply algorithms for examination, treatment, and control of these patients.

Specifically, I made contact with fellow pediatric cardiologists from the University Clinical Centre of Ljubljana, University Clinical Centre of Belgrade, Paediatrics Clinic Sarajevo, AKH Clinic in Vienna, and our common attitude is that these patients, following a detailed cardiovascular examination which, in addition to anamnesis data, includes establishing the $1^{\text {st }}$ day of disease or contact, result of polymerase chain reaction (PCR) or serological test on corona: Immunoglobulin/IgG/and immunoglobulin/IgM/, parameters of body weight, height, oxygen saturation, pulse, blood pressure, electrocardiogram/ECG/ auscultatory findings on the heart and complete examination of the child, with echocardiography which provides data on the morphology and hemodynamic of the heart with special reference to coronary blood vessels/possible dilatation, that is, aneurysms of coronary blood vessels/ myocardial infarction and cardiac output, are being evaluated with laboratory blood tests targeted to the heart muscle.

PCR is considered the gold standard for examining a child during corona 19 pandemic.

In children with mild form of corona or who have been in contact with an infected person, the recommendation is to pause all sports activities for a period of 4-6 weeks, followed by a serology test of the corona titer with IgG and $\operatorname{IgM}$.

If a child has no more symptoms, no fever, no shortness of breath, and no cough, has not been hospitalized for COVID-19 infection, cardiac screening is negative for myocarditis/myocardial ischemia, that is, no chest pain, chest tightness on exertion, unexplained crises of consciousness, unexplained severe dyspnea - shortness of breath, fatigue on exertion, and no new sensations in the chest if the cardiac murmur is not auscultated, and if answers to these questions are negative, the child can continue to play sports, gradually, in the next 14 days. Gradual involvement in sports is clearly defined and graded and is applied in the Institute of Sports Medicine in Sarajevo, providing detailed instructions to coaches.

In case of positive answers to cardiac screening questions, the child should be immediately referred to a pediatric cardiologist, who will suggest an X-ray of the heart and lungs, heart ultrasound, and possible computed tomography/CT/ of the heart, that is, a detailed evaluation of the cardiovascular system.

This approach has been agreed with colleagues from the Institute of Sports Medicine in Sarajevo. Of course, pediatric cardiologists, who completed their subspecialization in pediatric cardiology while I was working at the Paediatric Clinic in Sarajevo, and currently work in Bihać, Travnik, Tuzla, Mostar, Sokolac, Pale, and Zenica, are familiar with the above and we have been in constant communication.

Also, an interesting fact is that COVID-19 can be diagnosed, or contact can be proven in the pediatric population from newborns to 18 years of age. I have recently had a 5-day-old newborn patient who was tested positive for corona passed from his mother/in utero/, but fortunately he is in a good general condition, however, this new disease will require further monitoring and follow-up by professionals, pediatrician, pediatric cardiologist, and immunologist.

Corona serological test: A positive IgM titer/active process/ can last for weeks and sometimes even months.

A positive $\operatorname{IgG}$ titer is an indication of an old infection, that is, that the child was in contact with the virus or was suffering from COVID-19.

It is necessary to continue practicing physical distancing, washing hands, and of course wearing masks according to the instructions of the Disease Control Board of the Ministry of Health, World Health Organization, Royal College of Paediatricians and Child Health/UK/, with adequate vitamin intake, spending time in mountain fresh air, helping children with online classes, propagating a positive attitude toward the pandemic in the sense that it will not last forever and will end, encouraging children, to create as positive atmosphere at home as possible, learn new skills, read more, and walk at home. Child psychologists should be included in the treatment, as necessary.

\section{REFERENCES}

1. de Rose DU, Piersigilli F, Ronchetti MP, Santisi A, Bersani I, Dotta A, et al. Novel Coronavirus disease (COVID-19) in newborns and infants: What we know so far. Ital J Pediatr 2020;46(1):56.

https://doi.org/10.1186/s13052-020-0820-x.

2. Sporišević L, Mesihović-Dinarević $S$, Jogunčić A, Pilav A. Pediatric challenge of 
COVID-19. J Health Sci 2020;10:103-8.

3. World Health Organization. Coronavirus Disease (COVID-19), Situation Report-125. Geneva, Switerzland: World Health Organization; 2020. Available from: https://www. who.int/docs/default-source/coronaviruse/situation-reports/20200524-covid-19-sitrep-125.pdf. [Last accessed on 2020 May 15].

4. Cai X, Ma Y, Li S, Chen Y, Rong Z, Li W. Clinical characteristics of 5 COVID-19 cases with non-respiratory symptoms as the first manifestation in children. Front Pediatr 2020;8:258.

5. Royal College of Pediatrics and Child Health. Guidance-Paediatric Multisystem Inflammatory Syndrome Temporally Associated with COVID-19; 2020. Available from: $\quad$ https://www.rcpch.ac.uk/resources/guidance-paediatric-multisystem inflammatory-syndrome-temporally-associated-covid-19 https://doi.org/10.1111/jpc.15049. [Last accessed on 2020 May 17].

6. Dinarević S, Henein MY, Zaghal AA, Shinebourne EA, Gibson DG. Exercise Stress Echocardiography in Children with Kawasaki Disease-Left Ventricular Axis Selectively Impaired. Honolulu, Hawai: The $2^{\text {nd }}$ World Congress of Paedatric Cardiology and Cardiac Surgery; 1997. p. 87.

https://doi.org/10.1016/s0002-9149(98)00168-4.

7. Centers for Disease Control and Prevention. Multisystem Inflammatory Syndrome in Children (MIS-C) Associated with Coronavirus Disease 2019 (COVID-19). Atlanta: Centers for Disease Control and Prevention; 2020. Available from: https://www.emergency.cdc.gov/han/2020/han00432.asp.https://doi.org/10.1093/ofid/ofv131.60. [Last accessed on 2020 May 17].

8. Elliot $\mathrm{N}$ et al. Infographic, British Journal f Sport s Medicine, 2020/update 11/16/2020

\section{RELATED ARTICLES PUBLISHED IN JHSCI}

1. Sporišević L, Mesihović-Dinarević S, Jogunčić A, Pilav A. Coronavirus disease 2019 (COVID-19): a new pediatric challenge. JHSCI;10(2):103-8. 